\title{
OPERASIONAL PUKAT CINCIN KM. MALBERS 02 DI PERAIRAN TELUK TOMINI PROVINSI GORONTALO
}

\author{
Purse Seine Operations of Km. Malbers 02 in the Waters of Tomini Bay \\ Province of Gorontalo
}

\author{
Junneifer Aldo Maneking, Joneidi Tamarol, Fitria Fresty Lungari \\ Program Studi Teknologi Penangkapan Ikan Politeknik Negeri Nusa Utara
}

Email:

\begin{abstract}
Abstrak: Peningkatan efisiensi dan efektifitas operasi perangkapan ikan dengan pukat cincin diperlukan beberapa sarana dimana salah satunya yaitu dengan menggunakan alat bantu penangkapan ikan jenis rumpon. Selain rumpon dalam pengoperasiannya pukat cincin dilengkapi pula dengan perahu lampu. Penelitian ini dilaksanakan dengan metode deskriptif dengan dasar studi kasus dilapangan. Hasil penelitian menunjukan bahwa hasil tangkapan pukat cincin didominasi oleh ikan Layang (Decapterus sp), sebagian lagi ikan Cakalang (Katsuwonus pelamis) dan ikan Sunglir (Elegatis bipinnulatus). Dari hasil analisis data menunjukan bahwa alat tangkap pukat cincin KM.Malbers 02 dalam pengoperasiannya dibantu oleh alat bantu penangkapan ikan yakni rumpon dan perahu lampu serta alat tambahan penangkapan ikan yakni winch untuk penarikan tali cincin, power block untuk penarikan daging jaring dan caduk (sibu-sibu) untuk pengangkatan ikan hasil tangkapan. Waktu setting hingga hauling diantara 5-7 menit.
\end{abstract}

Kata kunci: Rumpon, Pukat Cincin, Perahu Lampu, Setting, Hauling

\begin{abstract}
Increasing the efficiency and effectiveness of the fishing operation using purse seine requires several means, one of which is the use of FAD fishing tools. In addition to FADs, in the operation of the purse seine, it is also equipped with a lamp boat. This research was conducted with a descriptive method based on field case studies. The results showed that the catch of purse seines was dominated by Layang fish (Decapterus sp), some Skipjack tuna (Katsuwonus pelamis) and, Sunglir fish (Elegatis bipinnulatus). From the results of the data analysis, it shows that KM.Malbers 02 's purse seine fishing gear is assisted in its operation by fishing aids, namely FADs and light boats as well as additional fishing tools, namely winches for pulling ring ropes, power blocks for pulling net meat, and cisterns (sibu-sibu) for the lifting of the caught fish. Time from setting to hauling is between 5-7 minutes.
\end{abstract}

Keyword: FAD, purse seine, lamp boat, setting, hauling

\section{PENDAHULUAN}

\section{Latar Belakang}

Pukat cincin (purse seine) merupakan jaring berkantong yang sangat efektif menangkap ikan pelagis bergerombol (pelagic shoaling species) dekat dengan permukaan air dan mempunyai kepadatan gerombolan yang tinggi. Sudirman dan Mallawa (2012), menjelaskan bahwa prinsip penangkapan ikan dengan pukat cincin yakni dengan melingkari gerombolan ikan dengan jaring, sehingga jaring membentuk dinding vertikal dengan demikian gerakan ikan kearah horizontal dapat dihalangi setelah itu bagian bawah dikerucutkan untuk mencegah larinya ikan kearah bawah jaring. Untuk meningkatkan efisiensi dan efektifitas operasi perangkapan ikan dengan pukat cincin diperlukan beberapa sarana dimana salah satunya yaitu dengan menggunakan alat bantu penangkapan ikan jenis rumpon. Dijelaskan oleh Subani dan Barus (1989), bahwa rumpon adalah suatu benda menyerupai pepohonan yang ditanam di suatu tempat di laut. 
Sedemikian pesatnya teknologi penangkapan ikan dengan pukat cincin sehingga penggunaan alat bantu penangkapan ikan sebagai media pengumpul ikan merupakan suatu keharusan. Demikian pula yang berlaku di perusahaan penangkapan ikan milik PT. Jaya Bitung Mandiri (Jabima) dimana salah satu armada penangkapan ikannya yakni KM. Malbers 02 . Dalam upaya menangkap ikan, daerah operasi penangkapan ikan mulai dari yang paling dekat yakni Perairan Tagulandang hingga menjangkau jauh sampai ke Perairan Teluk Tomini. Operasi penangkapan ikan di Perairan Teluk Tomini menggunakan rumpon dan perahu lampu untuk mendukung suksesnya operasi penangkapan ikan. Salah satu penentu keberhasilan penangkapan ikan dengan menggunakan pukat cincin yakni adanya rumpon sebagai media pengumpul ikan. Banyaknya ikan yang terkumpul di bawah rumpon dapat memungkinkan untuk diadakan operasi penangkapan ikan dengan pelingkaran jaring. Dengan adanya rumpon menjamin kepastian dalam proses penangkapan ikan.

\section{Tujuan Penelitian}

Penelitian ini bertujuan untuk:

1) Mendeskripsikan operasi penangkapan ikan dengan pukat cincin di KM Malbers 02;

2) Mendeskripsikan peran rumpon dan perahu lampu sebagai alat bantu penangkapan ikan;

3) Menginventarisir hasil tangkapan pukat cincin KM. Malbers 02.

\section{METODOLOGI PENELITIAN}

\section{Waktu dan Tempat Penelitian}

Penelitian ini dilaksanakan selama Bulan Juni - Juli 2019 dengan mengikuti trip operasi penangkapan ikan pukat cincin KM.Malbers 02 milik PT. Jaya Bitung Mandiri Kota Bitung Sulawesi Utara yang dioperasikan di Teluk Tomini Provinsi Gorontalo.

\section{Bahan dan Alat Penelitian}

Untuk mendukung penelitian ini maka bahan dan peralatan yang digunakan yakni 1). Rumpon dan perahu lampu sebagai alat bantu penangkapan ikan; 2). Kapal penangkap ikan dengan alat tangkap pukat cincin dan kelengkapannya, 3). Kamera untuk dokumentasi, 4). Laptop sebagai pengolah data yang dilengkapi dengan aplikasi google earth untuk memetakan posisi daerah penangkapan ikan, dan 5). Global Positioning System (GPS) yang digunakan untuk mengetahui posisi daerah pengoperasian purse seine.

\section{Metode Penelitian}

Metode penelitian ini didasarkan pada penelitian deskriptif dengan dasar studi kasus di lapangan. Pengambilan data dilakukan dengan mengamati proses pengoperasian alat tangkap pukat cincin.

\section{Teknik Pengumpulan Data}

Pengumpulan data dilakukan dengan mencatat dan mendokumentasikan urutan pengoperasian alat tangkap ikan pukat cincin KM. Malbers 02 yang dimulai dari persiapan hingga penanganan ikan di palka.

\section{Analisis Data}

Data yang telah dikumpulkan dideskripsikan menurut urutan pengoperasian alat tangkap pukat cincin sedangkan hasil tangkapan dianalisis lewat tabel dan diagram. Hubungan antara urutan proses penangkapan ikan dan hasil tangkapan yang didapat dibandingkan dengan hasil-hasil penelitian sejenis terdahulu.

\section{HASIL DAN PEMBAHASAN}

\section{Deskripsi Umum KM Malbers 02}

KM. Malbers 02 (tanda selar GT.30 No.1823/KKb 2013 KKb No.1355/N) berbobot mati 30 GT memiliki dimensi utama panjang keseluruhan (LOA): 27,70 m, 
lebar (Breadth): 6,70 m dan dalam (Depth): 2,35 m. Menggunakan mesin dalam (inboard) jenis Nisan 300 PK dan dilengkapi dengan peralatan tambahan penunjang penangkapan ikan seperti kapstain (power block) untuk mengangkat badan jaring; winch untuk menarik tali cincin; Caduk ikan (sibu-sibu) untuk mengangkat ikan dari jaring ke palka ikan; perahu ayuda (skiff boat) untuk membantu saat penawuran jaring.

Brandt (1984) menjelaskan bahwa ada dua tipe purse seine yaitu purse seine tipe Amerika dan purse seine tipe Jepang. Purse seine tipe Amerika berbentuk empat persegi panjang dengan bagian pembentuk kantong berada ditepi jaring sedangkan purse seine tipe Jepang berbentuk empat persegi panjang dengan bagian bawah jaring berbentuk busur lingkaran dan bagian pembentuk kantong terletak di tengah jaring. Jaring yang digunakan di KM. Malbers 02 berbentuk segi empat atau empat persegi panjang dengan kantong bagian tengah termasuk dalam tipe pukat cincin Jepang, dimana bagian akhir proses penangkapan ikan hasil tangkapan berada di tengah jaring.

Hasil penelitian yang dilakukan oleh Rahmat dan Witdiarso (2017), menjelaskan bahwa Teluk Tomini yang termasuk dalam Wilayah Pengelolaan Perikanan (WPP) 715 mempunyai potensi perikanan yang cukup melimpah terutama untuk sumber daya ikan pelagis. Usaha penangkapan ikan pelagis kecil oleh nelayan Teluk Tomini pada umumnya menggunakan alat tangkap pukat cincin mini (mini purse seine), sedangkan untuk ikan pelagis besar menggunakan pancing ulur (hand line).

\section{Nelayan Pukat Cincin}

Karman (2008), menjelaskan bahwa nelayan pada perikanan pukat cincin (purse seine) adalah orang yang ikut dalam operasi penangkapan ikan secara langsung maupun tidak langsung. Dalam operasi penangkapan ikan, masing-masing nelayan memiliki tugas tersendiri sehingga operasi penangkapan ikan dapat berjalan lancar. Di KM.Malbers 02 jumlah Anak Buah Kapal (ABK) atau disebut juga crew kapal yang tercatat saat penangkapan ikan sejumlah 29 orang dengan tugas dan perannya masing-masing ketika diadakanya operasi penangkapan ikan. Kru kapal tersebut yakni: 1 orang Nakhoda (fishing master); 1 orang Kepala Kamar Mesin (KKM); 2 orang ABK yang berperan sebagai orang air; 1 orang operator winch; 1 orang operator power block; 2 orang koki kapal; sisanya berperan sebagai kru biasa. Jika melihat jumlah kru kapal (29 orang) maka jumlah tersebut dianggap melebihi karena fungsi tenaga manusia sebenarnya sudah tergantikan dengan fungsi mesin (winch, power block) yang dioperasikan. Namun hal demikian menjadi wajar karena saat wawancara selain kru biasa juga ikut tenaga sukarela (volunteer) yang kesemuanya tercatat dalam pengurusan ijin berlayar.

\section{Peran Rumpon Sebagai Alat Bantu Penangkapan} Ikan

Rumpon merupakan alat bantu dalam penangkapan ikan yakni dengan mengumpulkan ikan sehingga ikan terkonsentrasi. Subani (1986), menjelaskan bahwa prinsip penangkapan ikan dengan menggunakan alat bantu rumpon adalah untuk mengumpulkan ikan, sehingga nantinya ikan akan lebih mudah ditangkap. Diduga ikan tertarik dan berkumpul disekitar rumpon karena rumpon berfungsi sebagai tempat untuk berlindung dan mencari makan. Adanya ikan disekitar rumpon menciptakan suatu hubungan makan dan dimakan, dimulai dengan tumbuhnya bakteri dan mikroalga sejak rumpon dipasang diperairan. Selanjutnya Sudirman (2013), menekankan bahwa rumpon atau disebut juga dengan FAD (fish agregation device) merupakan suatu alat bantu penangkapan ikan yang berfungsi untuk memikat ikan 
agar berkumpul dalam suatu area penangkapan (catchable area).

Sehingga dengan fungsi rumpon tersebut nelayan atau pelaku usaha perikanan tangkap dapat lebih efisien dan efektif dalam menangkap ikan. Nelayan tidak lagi dalam posisi mencari ikan akan tetapi memanfaatkan rumpon yang telah berisi ikan tersebut. Hal tersebut diyakini dapat mengurangi beban nelayan terhadap Bahan Bakar Minyak (BBM). Hal ini sejalan dengan penjelasan Jeujunan (2016), bahwa lama pelayaran untuk mencari posisi ikan (fish searching) menjadi berkurang karena kapal ikan biasanya akan diarahkan nelayan langsung pada lokasi dimana rumpon dipasang.

Rumpon yang digunakan sebagian merupakan rumpon milik perusahaan dan sebagiannya lagi milik nelayan setempat. Di perairan Teluk Tomini banyak tersebar rumpon sehingga daerah tersebut merupakan daerah potensial penangkapan ikan terutama untuk pukat cincin.

\section{Peran Perahu Lampu Sebagai Alat Bantu Penangkapan Ikan}

Perahu lampu yang digunakan menggunakan daya listrik sebesar 12 volt 50 ampere dilengkapi dengan balon lampu yang memancarkan daya sebesar 5 watt sebanyak 4 buah. Fungsi perahu lampu ini yaitu untuk menggantikan cahaya lampu dari kapal ikan ketika akan dimulainya proses penangkapan ikan. Adanya cahaya lampu dari perahu lampu dapat mempengaruhi ikan agar ikan dapat terkumpul pada daerah suatu penangkapan ikan.

\section{Tahapan Pengoperasian Alat Tangkap}

Tahapan pengoperasian alat tangkap purse seiner ini yaitu terdiri dari persiapan, setting, pursing, hauling, handlling dan brailling. Untuk menuju daerah penangkapan ikan dibutuhkan waktu kurang lebih 18 jam dengan jarak tempuh 100 mil dari pelabuhan perusahaan. Kecepatan kapal rata-rata 7-8 knot/jam. Daerah penangkapan ikan (DPI) yang dituju yakni terletak di posisi geografis $00^{\circ} 30^{\prime} 500^{\prime \prime}$ LS dan $128^{\circ}$ 30'500' BT. Dalam perjalanan menuju DPI kapal akan menggandeng perahu ayuda (skiff boat) dan perahu lampu. Ketika kapal penangkap ikan tiba dilokasi penangkapan ikan pada sore hari maka kapal akan langsung mengikat tali di rumpon. Lampu kapal menjadi menjadi sarana penerangan sementara untuk mengumpulkan ikan, sambil perahu lampu disiapkan menjelang dimulainya operasi penangkapan ikan.

Operasi penangkapan ikan (setting) dimulai pada pukul 04.00 dini hari yang ditandai dengan dinyalakannya perahu lampu sebagai pengganti perahu kapal (Gambar 1). Perahu lampu yang disiapkan diharapkan dapat menarik perhatian ikan sambil memanfaatkan daya tarik ikan terhadap cahaya lampu (phototaksis positive) sehingga ikan dapat terkumpul atau terkonsentrasi.

Untuk kelancaran proses penangkapan ikan maka kapal akan memindahkan rumpon sebab jika ada rumpon tidak bisa dilakukan operasi penangkapan ikan karena jaring akan tersangkut pada tali rumpon. Proses pemindahan rumpon dimulai dengan memindahkan ponton yang dilengkapi deng an atraktor (gara-gara) ke perahu lampu. Rumpon diberi pelampung lain atau pelampung tanda (bui) untuk seterusnya akan digandeng dengan kapal menjauh dari perahu lampu. Menggandeng rumpon tersebut haruslah melawan arus sehingga rumpon tersebut tidak terbawa arus. Perahu lampu akan menjaga intensitas cahaya agar ikan tidak lari atau terpencar sehingga ikan tetap terkonsentrasi di bawah cahaya lampu. Setelah rumpon selesai dijauhkan maka kapal akan kembali untuk mendekati perahu lampu. Proses menggandeng rumpon merupakan hal yang berbeda jika dibandingkan dengan pengoperasian pukat cincin yang ada ditempat lain. Karman (2008) menjelaskan bahwa pengopersian alat tangkap dilakukan setelah 
perahu lampu menggiring ikan menjauhi rumpon sekitar kurang lebih $100 \mathrm{~m}$.

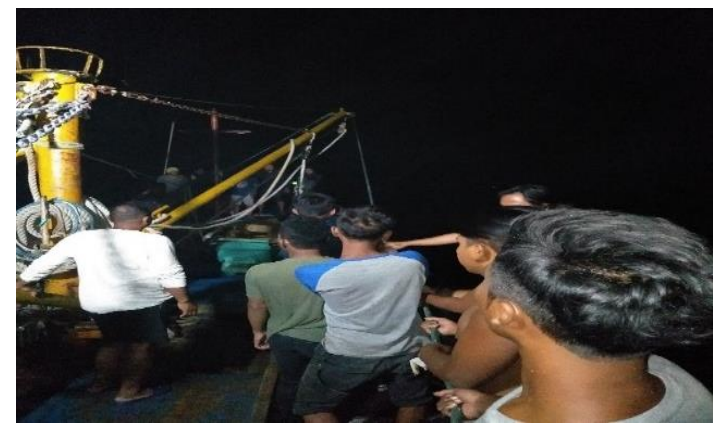

Gambar 1. Setting

Pengawasan arah arus dan ikan dilakukan oleh dua (2) ABK yang akan turun ke air dengan menyelam untuk mengamati arah pergerakan ikan. Jika arah kepala ikan sudah diketahui akan diberitahukan kepada nakhoda atau tonaas (fishing master). Dua orang ABK tadi akan mengambil posisi di samping perahu lampu.

Proses penangkapan ikan dilakukan dengan penawuran jaring dimana jaring dilingkar di sekitar tempat ikan yang sudah diawasi tadi (Gambar 2).

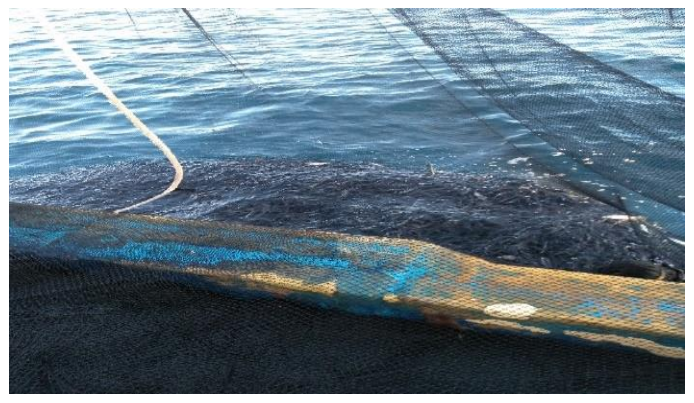

Gambar 2. Penawuran jaring

Bagian pertama yang diturunkan yaitu pelampung tanda kemudian tali kerut dan cincin, berikut diikuti dengan pemberat. Pemberat diturunkan diawasi oleh 1 orang ABK. Sambil jaring diturunkan maka kapal berputar melingkari kawanan ikan. Badan jaring dan pelampung secara otomatis akan ikut terjatuh sampai ujung tali akan bertemu dengan ujung tali pertama yang dilepas.
Setelah proses penurunan jaring selesai maka dilakukan penarikan tali kerut atau tali cincin dengan mengunakan bantuan mesin winch. Setelah tali kerut sudah terkunci dan jaring membentuk seperti kantong maka dilakukan penarikan badan jaring (haulling) dengan cara bersamaan dengan pelampung dan pemberat mengunakan bantuan mesin power blok (Gambar 3).

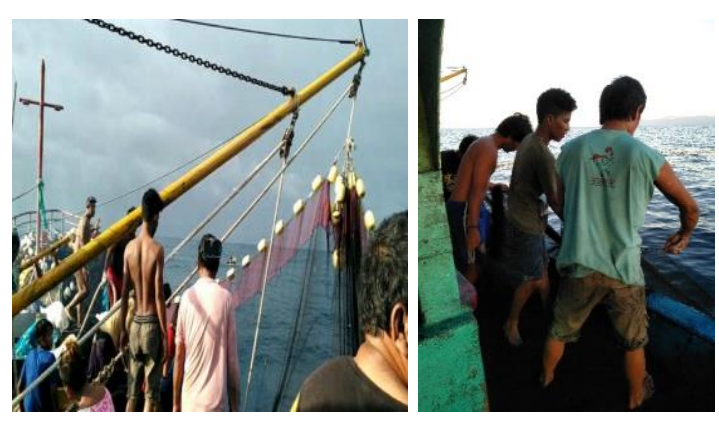

\section{Gambar 3. Haulling}

Jaring ditarik mendekati kapal agar memudahkan dalam pengambilan hasil tangkapan. Pengangkatan ikan dilakukan dengan mengunakan caduk ikan yang disebut dengan sibu-sibu. Sibu-sibu tersebut diikat dengan tali dan disambungkan dengan power block untuk mengangkat ikan yang ada di dalam jaring atau brailing (Gambar 4).

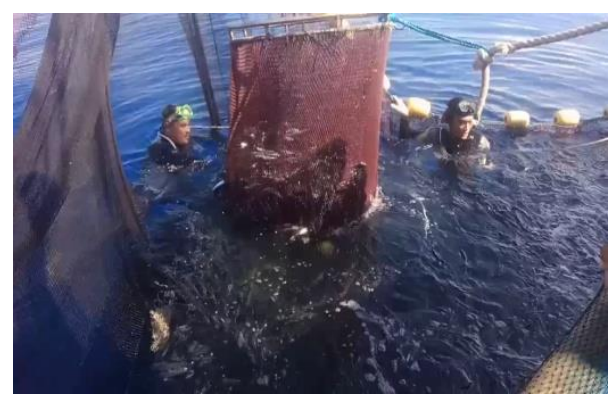

Gambar 4. Brailing

Ikan yang sudah diangkat dari dalam jaring selanjutnya diturunkan kearah mulut palka. Setelah ikan dimasukan kedalam palka maka langsung diberikan es dan garam agar ikan dapat bertahan dan tidak rusak sampai ketempat pendaratan ikan. 


\section{Hasil Tangkapan KM. Malbers 02}

Selama empat kali setting di perairan Teluk Tomini didapat hasil tangkapan sejumlah 9 ton yang didominasi oleh ikan Layang (Decapterus sp), selebihnya ikan Sunglir (Elegatis bipinulatus).

Tingkah laku ikan dalam gerombolan yang sudah dikurung dengan alat tangkap purse seine, akan selalu berusaha untuk meloloskan diri baik kearah horizontal maupun vertikal. Jika satu ekor saja dapat meloloskan diri dari jaring, maka semua anggota kelompok dapat meloloskan diri (Baskoro $d k k$, 2011). Dengan demikian keberhasilan operasional pukat cincin didukung pula oleh waktu pelingkaran jaring yang memadai dan efektif. Dari tabel tersebut diketahui bahwa waktu pelingkaran jaring antara 5-7 menit sekali setting. Mempercepat waktu setting merupakan kunci sukses pengoperasian pukat cincin.

\section{KESIMPULAN}

Dari penelitian ini diambil kesimpulan sebagai berikut:

1. Operasi penangkapan ikan dengan pukat cincin di KM.Malbers 02 yakni terdiri dari tahap konsentrasi kawanan ikan, persiapan alat tangkap, setting, dan hauling.

2. Peran rumpon dan perahu lampu yakni pukat cincin di KM.Malbers 02 yakni mengumpulkan ikan pada suatu areal penangkapan ikan.

3. Hasil tangkapan pukat cincin di KM.Malbers 02 yakni terdiri ikan Layang (Decapterus sp); pelamis) dan ikan Sunglir (Elegatis bipinnulatus).

\section{DAFTAR PUSTAKA}

Baskoro, M., dan Taurusman.,A.Am., 2011. Tingkah Laku Ikan: Hubungannya dengan Ilmu dan Teknologi Perikanan Tangkap. Lubuk Agung. Bandung. 258 hal.

Brandt, A.V., 1984. Fish Catching Methods of The World. Fishing News Books. Ltd, London. 418 hal.

Jeujanan.,B. 2016. Rumpon Sebagai Alat Pengelolaan Perikanan Pelagis Di Perairan Kepulauan Kei. Disertasi. Sekolah Pasca Sarjana Institut Pertanian Bogor. 195 hal.

Karman.,A. 2008. Pengembangan Perikanan Mini Purse Seine (Soma Pajeko) Berbasis Rumpon Di Sekitar Pulau Mayau Kota Ternate Provinsi Maluku Utara. Disertasi. Sekolah Pasca Sarjana Institut Pertanian Bogor. 119 hal.

Rahmat.,E dan Witdiarso., B. 2017. Operasional Alat Tangkap Pukat Cincin Mini (Mini Purse Seine Di Teluk Tomini Oleh Nelayan Di Gorontalo. Buletin Teknik Litkayasa Sumber daya dan Penangkapan Volume 15 Nomor 1 Juni 2017 p-ISSN:1693-7961 e-ISSN:25412450 .

Subani., W. 1983. Penggunaan Lampu Sebagai Alat Bantu Penangkapan Ikan. Laporan Penelitian Perikanan Laut (Marine Fisheries Report). Balai Penelitian Perikanan Laut Departemen Pertanian. Jakarta. Hal 45-68.

Subani W dan H.R Barus. 1989. Alat Penangkapan Ikan dan Udang Laut di Indonesia. Jurnal Penelitian Perikanan Laut No. 35 tahun 1988/1989 Edisi Khusus. Balai Penelitian Perikanan Laut. Badan Penelitian dan Pengembangan Pertanian. Departemen Pertanian. Jakarta. 248 hal.

Sudirman, H., dan Mallawa,A., 2012. Teknik Penangkapan Ikan (edisi revisi). PT. Rineka Cipta. Jakarta. 168 hal.

Sudirman, H.,2013. Mengenal Alat dan Metode Penangkapan Ikan. PT. Rineka Cipta. Jakarta. 255 hal. 